\title{
Kontribusi Perspektif Ekonomi Feminis dalam Pendidikan Ekonomi Keluarga Suku Melayu Jambi untuk Menanamkan Perilaku Ekonomi Pancasila
}

\author{
Mayasari \\ Dosen FKIP Universitas Batanghari \\ Correspondence email: mhmayahendra@gmail.com
}

\begin{abstract}
The aims of this study was to determine the contribution of a feminist economic perspective in the family economic education of the Jambi Malay to instill the Pancasila economic life as seen from the mindset, attitude and behavior patterns. Research methods using qualitative methods with a phenomenological approach. The subjects of this study were housewives as key informants namely SHJ, RTW, RTSE, IDRI, SILSY, and FAU in providing economic education to embed Pancasila economic life. The results of this study are the contribution of a feminist economic perspective in this study is the perspective of housewives viewed from the mindset, attitude patterns, and behavior in family economic education teaches that it must prioritize adat bersendi syara', syara'bersendi kitabullah that is combined with values -cultural values such as the value of helping to help, the value of togetherness, the value of cooperation, the value of responsibility, the value of surrender, the value of planning, the value of opportunity, and the value of hard work. These values are applied in carrying out economic life in both the family and community environment. Conclusion family economic education provided from the point of view of the Malay housewife has instilled the Pancasila economic behavior.
\end{abstract}

Keyword: feminist economy; family economic education; Pancasila economic behavior

\section{PENDAHULUAN}

Gerakan ekonomi feminis membuktikan bahwa perempuan memiliki peranan penting seperti saat ini. Ekonomi feminis itu sendiri adalah suatu gerakan yang meliputi studi peran gender dalam perekonomian dari perspektif pembebas dan bekerja kritis diarahkan pada penerapannya dalam kegiatan ekonomi. Ekonomi feminism bersifat altruism artinya mendahulukan kepentingan orang lain dari pada kepentingan dirinya. Dalam perkembanganya ekonomi feminim terbagi menjadi dua bagian yakni domestic (ibu rumah tangga) dan go public (wanita karir). Dari adanya gerakan ekonomi feminis ini, tak bisa dipungkiri juga memiliki peran besar dalam suatu Negara untuk mencapai pertumbuhan dan pembangunan ekonomi suatu Negara.

Di Indonesia peran perempuan begitu kompleks dengan sifat feminimnya memiliki daya tarik tersendiri yang cenderung memiliki ketekunan, ketelitian, keluwesan dan terampil dalam mengerjakan tugas-tugas mereka. Penulisan ini berasal dari kerisauan saya tentang arus globalisasi di atas yang semakin pesat membawa dampak pendidikan ekonomi kearah liberalisasi sehingga generasi penerus melupakan jati diri bangsanya yang memiliki faham ekonomi Pancasila. Oleh karena itu ekonomi feminism yang dilakukan perempuan memegang peranan penting dalam memajukan pertumbuhan dan pembangunan ekonomi bangsa. Ekonomi feminis dalam penulisan ini adalah perempuan sebagai ibu rumah tangga yang terkadang terpinggirkan, padahal mereka memiliki peranan penting dalam memajukan pembangunan ekonomi Indonesia yang beridiologikan pancasila. Melalui proses pendidikan ekonomi keluarga yang di berikan oleh seorang ibu, akan berdampak besar bagi anggota keluarganya khususnya anak-anak sebagai generasi penerus bangsa dalam menghadapi globalisasi ekonomi. Sehingga anggota keluarganya tidak terjerumus dalam arus modernisasi yang menyesatkan dan menjauhkan pola pikir, sikap dan perilaku dari kehidupan ekonomi pancasila.

Kiprah perempuan dalam sector domestic, sebagai contoh di lingkungan keluarga perempuan memiliki peran yang amat penting dalam pembelajaran bagi anggota keluarganya untuk menanamkan perilaku ekonomi pancasila, apalagi mengingat arus globalisasi ekonomi liberal yang sangat memprihatinkan yang menggeser pentingnya perilaku ekonomi pancasila. Oleh karena itu perilaku ekonomi pancasila perlu ditanamkan sejak dini untuk membentuk pribadi generasi penerus bangsa yang beridiologikan pancasila. Pendidikan dalam menanamkan perilaku ekonomi pancasila yang paling dekat adalah pada lingkungan keluarga, orang tua, terutama ibu adalah orang yang paling berperan membentuk perilaku tersebut. Seperti kita ketahui fenomena yang terjadi saat ini adalah arus globalisasi dan perdagangan bebas begitu cepat masuk ke dalam masyarakat terutama di kalangan pelajar. Pengaruhnya terhadap generasi muda begitu kuat dalam mempengaruhi perilaku konsumsi, karena para generasi muda termasuk segmen pasar yang berpotensi. Pendidikan ekonomi di keluarga perlu dipelajari agar generasi muda tidak terjerumus pada hal yang negative dari adanya arus globalisasi. Disinilah dibutuhkan peran perempuan sebagai ibu rumah tangga untuk memberikan pelajaran pendidikan ekonomi keluarga dalam mengatur intensitas kebutuhan anggota keluarganya.

Seyogyanya pemahaman tentang ekonomi feminis dalam pendidikan ekonomi keluarga perlu ditanamkan agar, perempuan masyarakat Jambi dapat menunjukan eksistensinya di segala bidang berdasarkan idiologi yang dianut bangsa Indonesia yakni idiologi pancasila.

\section{Landasan Teori}

Pentingnya landasan teori dalam penelitian ini agar fokus penelitian sesuai dengan kenyataan di lapangan dan untuk memberikan gambaran umum tentang latar penelitian dan sebagai bahan pembahasan hasil penelitian. 


\section{Pendidikan Ekonomi Keluarga}

Dari segi etimologis, pendidikan berasal dari bahasa Yunani "paedagogike". Ini adalah kata majemuk yang terdiri dari kata "pais" yang berarti "anak" dan kata "ago" yang berarti "aku membimbing". Jadi paedagogike berarti aku membimbing anak. Saroni (2011) menyatakan bahwa, "pendidikan merupakan suatu proses yang berlangsung dalam kehidupan sebagai upaya untuk menyeimbangkan kondisi dalam diri dengan kondisi luar diri. Proses penyeimbangan ini merupakan bentuk survive yang dilakukan agar diri dapat mengikuti setiap kegiatan yang berlangsung dalam kehidupan." Pendidikan juga merupakan salah satu bentuk investasi manusia yang dapat meningkatkan derajat kesejahteraan masyarakat. Kyridis, et al. (2011) mengungkapkan bahwa "for many years the belief that education can increase social equality and promote social justice, has been predominant".

Istilah ekonomi berasal dari bahasa yunani yaitu Oikonomia yang terdiri dari dua suku kata yaitu oikos dan nomos. Oikos berarti rumah tangga, sedangkan nomos berarti aturan. Sehingga oikonomia mengandung arti aturan rumah tangga. Oikonomia mempunyai arti aturan yang berlaku untuk memenuhi kebutuhan hidup dalam suatu rumah tangga (Sukwiaty, 2007). Seiring dengan perkembangan zaman dan ilmu pengetahuan muncullah ilmu yang disebut ilmu ekonomi. Menurut Samuelson (2003) ilmu ekonomi adalah kajian bagaimana masyarakat menggunakan sumber daya yang langka untuk memproduksi komoditi-komoditi yang berharga dan mendistribusikannya kepada masyarakat luas.

Pengertian keluarga berdasarkan asal-usul kata yang dikemukakan oleh Ki Hajar Dewantara (Abu\&Nur, 2001), bahwa keluarga berasal dari bahasa Jawa yang terbentuk dari dua kata yaitu kawula dan warga. Menurut Mattessich dan Hill (Zeitlin,1995), keluarga merupakan suatu kelompok yang berhubungan kekerabatan, tempat tinggal, atau hubungan emosional yang sangat dekat yang memperlihatkan empat hal (yaitu interdepensi intim, memelihara batas-batas yang terseleksi, mampu untuk beradaptasi dengan perubahan dan memelihara identitas sepanjang waktu, dan melakukan tugastugas keluarga). Keberadaan keluarga inti adalah untuk sebagian besar ditentukan oleh alam.

Pendidikan ekonomi keluarga tidak hanya mendidik anggota keluarga bahkan samapi mengurusi kegiatan ekonomi seperti konsumsi untuk memenuhi kebutuhan keluarga sampai mengaturnya agar kesejahteraan keluarga bisa terpenuhi dengan pemasukan yang dimiliki oleh keluarga. Hal ini senada dengan yang dikatakan oleh Bryant (1995) bahwa "Consumption, in short, can be understood this way: households make decisions about what products and services to buy based on combinations or bundles of goods that will maximize welfare, subject to financial constraints".

Pendidikan ekonomi keluarga dalam artikel ini adalah pendidikan ekonomi yang dilakukan dari dalam keluarga itu sendiri. Anggota keluarga memberikan pembelajaran ekonomi kepada anak-anaknya tentang ekonomi mulai dari mereka bangun tidur sampai tidur kembali melakukan kegiatan ekonomi yang efektif dan efesien untuk memenuhi intensitas kebutuhan keluarga. Sebagai salah satu contohnya adalah tentang pendidikan dalam mengelola pendapatan yang digunakan untuk memenuhi kebutuhan keluarga yang ditransferkan kepada kebutuhan anak-anak.

\section{Ekonomi Feminist}

Dari perspektif ekonomi feminis, yang lebih inklusif pemahaman tentang berbagai dampak pada laki-laki dan wanita akan menghasilkan perumusan gender sadar daripada respon kebijakan gender buta resesi dan pemulihan. Menurut Berik et.al (2009) bahwa feminist economics states that it is important to consider equality of outcomes alongside equality of opportunities, due to the fact that "systemic inequality in outcomes contributes to unequal power and, as a result, unequal opportunities" and vice versa. Ekonomi feminis itu sendiri memiliki tujuan sebagi kodratnya seorang perempuan, mereka harus tetap memiliki kewajiban-kewajiban seperti layaknya perempuan sejati, mengurus rumah tangga keluarga mereka tetapi mereka juga harus memiliki kestaraan gender dan kesempatan yang sama untuk memperoleh pengetahuan dan pendidikan yang layak sebagaimana kaum laki-laki. Seperti yang dikemukakan oleh Sweetman (2008) sebagai berikut:

In addition to their reproductive role, it is increasingly common for women to undertake paid work; yet feminist economists argue that due to the universal perception of the 'male-breadwinner', the contribution women make to their households is perceived by many to be relatively insignificant. This "perpetuates inequality between women and men, because it fundamentally weakens women's bargaining power in marriage and the family"

Penulisan ini berusaha memahami tentang "Peranan Perempuan " dalam berbagai kegiatan yang langsung menghasilkan nafkah ataupun yang tidak langsung tetapi memberi peluang bagi orang lain untuk berperan lebih jauh dalam keaiatan nafkah.

\section{Perilaku Ekonomi Pancasila}

Perilaku ekonomi (economic behavior) adalah tindakan-tindakan (actions) atau reaksi-reaksi (reactions) dari suatu objek yang berupa baik rasionalitas, moralitas, gaya hidup, efisiensi dalam aktivitas konsumtif, dan efektivitas dalam aktivitas produktif. Dalam penulisan ini tindakan-tindakan yang akan dibahas, dianalisis, dan dikaji adalah tindakan tentang rasionalitas, moralitas daan gaya hidup berdasarkan ekonomi pancasila yang diberikan dalam pendidikan ekonomi keluarga.

\section{a. Rasionalitas Dalam Ekonomi Pancasila}

Pada hakekatnya rasionalitas dalam pendidikan ekonomi pancasila membelajarkan anggota keluarga untuk bertindak rasional dalam melakukan tindakan ekonomi. Mempelajari ilmu ekonomi itu adalah sesuatu yang kompleksitas agar anggota keluarga dapat menentukan pilihan-pilihan yang tepat dengan keterbatasan sumber daya ekonomi untuk memenuhi kebutuhan yang vital terlebih dahulu baru kemudian dapat memenuhi kebutuhan yang lain karena pada dasarnya manusia memiliki kebutuhan yang sangat tak terbatas, maka diperlukanlah rasionalitas untuk self interest (kepentingan pribadi) sehingga dapat terpenuhi. Kelemahan dari rasionalitas ini membentuk siswa menjadi materialis. Namun tidak semua 
pembelajaran ekonomi dirasionalitaskan karena dalam pembelajaran ekonomi terdapat moralitas ekonomi yang dapat mendidik siswa lebih bermoral menjadi economicus man (manusia ekonomi).

\section{b. Moralitas dalam Ekonomi Pancasila}

Memahami konsep moralitas eknomi, harus memahami terlebih dahulu konsep dari moral itu sendiri. Menurut Mayasari (2015) Economic Morality is part of the economic behavior with regard to a person's attitudes and economic action in interaction with another person or groups of people, who emphasize the caring person against all others' existance.

Konsep moral di atas, menurut penulis mengandung arti bahwa moralitas ekonomi bagian dari perilaku ekonomi yang berkaitan dengan sikap dan tindakan ekonomi seseorang dalam interaksinya dengan orang lain atau kelompok orang, yang menekankan pada kepedulian seseorang terhadap keberadan orang lain. Cara membangun moralitas ekonomi pancasila tersebut menurut Sudarmanto (2010) ekonomi pancasila sebagai ekonomi kelembagaan, maka harus menjunjung tinggi nilai-nilai dari kelembagaan pancasila yang terdiri dari lima asas substansi yang membangun moralitas ekonomi pancasila diantaranya adalah (1) etika, (2) kemanusiaan, (3) nasionalisme, (4) kerakyatan/demokrasi, dan (5) keadilan sosial, harus dipertimbangkan dalam model ekonomi yang disusun.

\section{c. Gaya Hidup dalam Ekonomi Pancasila}

Menurut Sustina (2002;145) Gaya hidup di definisikan lebih luas sebagai cara hidup yang di identifikasi oleh bagaimana orang menghabiskan waktu mereka (aktifitas), apa yang mereka anggap penting dalam lingkungannya (ketertarikan) dan apa yang mereka pikirkan tentang diri mereke sendiri dan juga dunia disekitarnya (pendapat). Dapat disimpulkan bahwa gaya hidup adalah pola hidup seseorang yang dinyatakan dalam kegiatan, minat dan pendapatnya dalam membelanjakan uangnya dan bagaimana mengalokasikan waktu. Lantas gaya hidup menjadi segala-galanya sebagai suatu symbol citra, image, dan estetika atas realitas ekonomi apalagi ideologi (etika). Pragmatis gaya hidup telah mengubah pola pikir, sikap dan perilaku masyarakat Indonesia yang tidak lagi menjadikan pancasila sebagai selectif incomparatif atas segala-gala nilai-nilai hidup dan berkembang dalam konteks kekinian. Oleh karena itu kita harus membenahi gaya hidup kita sesuai dengan perilaku ekonomi.

\section{METODE PENELITIAN}

Penelitian ini merupakan penelitian yang bersifat kualitatif, yaitu suatu pendekatan penelitian yang menghasilkan data diskriptif berupa data-data tertulis atau lisan dari orang-orang dan perilaku yang dapat diamati (Moleong, 2009). Pemilihan informan kunci (key informan) didasarkan pada informasi dari ketua RT yang ada pada masyarakat melayu Jambi yang mengetahui tentang kondisi dan situasi masyarakat melayu jambi diantaranya SHJ, RTW, RTSE, IDRI, SILSY, dan FAU sebagai ibu rumah tangga. Maka ditetapkan informasi selanjutnya yang dimulai dari informan pertama yaitu ibu rumah tangga yang berada di lingkungan sekitar, terus keinforman selanjutnya yaitu kepala rumah tangga dalam hal ini ayah, dan masyarakat yang ada disekitar masyarakat melayu jambi, sampai tidak diperlukan lagi informan-informan lainnya, karena informan sebelumnya sudah memberikan informasi yang dianggap relatif sama.

\section{HASIL DAN PEMBAHASAN}

Perspektik ekonomi feminis dalam penelitian ini adalah sudut pandang dari kiprah dan peran ibu rumah tangga di era globalisasi dan moderisasi yang memiliki beban yang multidimensi. Sehingga, kiprah dan peran IRT bukan hanya menjalankan peranya secara kodrati untuk melahirkan, mengurus, dan mendidik anak, melaksanakan pekerjaan rumah serta melayani suami saja tetapi ikut serta membantu suami untuk menopang perekonomian keluarga dengan membantu mencari nafkah, baik IRT yang bekerja di ranah domestik ataupun publik.

Kiprah dan peran IRT (KPIRT) suku melayu Jambi dulu hanya menjalankan kodratnya sebagai perempuan melahirkan, merawat, mengasuh, dan mendidik anak, melayani suami dan pekerjaan rumah lainya, mereka tidak diberi akses dan kebebasan untuk ke ranah publik. Jika dikaitkan dengan teori, hal tersebut sejalan dengan pemikiran Krishnaraj (2006):

"All women spend more time on housework, have more responsibility for child rearing, have less access to many social and material resources, and have less access to public spaces and public power".

Pemikiran di atas menceritakan situasi dan kondisi dimana perempuan (IRT) hanya bisa menjalankan kiprah dan peranya sebagai kodratnya perempuan dan tidak diberi kesempatan untuk terlibat dengan akses ke ruang publik. Hal ini berbanding terbalik dengan kiprah IRT di era sekarang ini yang memiliki beban yang lebih berat dari laki-laki selain menjalankan kodratnya, IRT juga terlibat dengan akses ke ruang publik, tetapi tidak melupakan tanggung jawabnya akan kiprah dan peranya sebagai IRT di rumah. Senada dengan teori yang dikemukakan Lantara (2015) tentang:

"Burden and responsibility of a female leader or other career woman are huge. Woman shall not only have a career, but she also has responsibility to be a housewife at home. Such responsibility, indeed, is not belong to man.

Berdasarkan hal tersebut, jelaslah bahwa kiprah dan peran dari IRT suku melayu Jambi mengalami perubahan seiring dengan perkembangan zaman. Untuk menjalankan kiprah dan peranya tersebut dibutuhkan suatu pola pikir, pola sikap dan perilaku dari IRT yang berdasarkan adat bersendi syara', syara'bersendi kitabullah. Dalam kaitanya akan KPIRT suku melayu Jambi yang terjadi pada informan SHJ, RTW, RTSE, IDRI, SILSY, dan FAU berdasarkan pola pikir mereka bahwa Pola pikir yang dimiliki IRT suku melayu Jambi akan KPIRT yang di jalankanya dimulai sejak memiliki keturunan. Banyak nilai yang terkandung dalam menjalankan KPIRT berdasarkan pola pikirnya diantaranya ibu pada suku melayu 
Jambi di dalam keluarga sebagai jantung ekonomi keluarga, manajer, menjaga persatuan keluarga, memegang kendali keuangan, berlandaskan kepentingan anggota dan sosial, berpedoman pada nilai-nilai agama dan norma adat kebudayaan, penggerak roda perekonomian keluarga, memanfaatkan potensi ekonomi sekitar, memberikan ketentraman batin dan kerjasama antar anggota keluarga dan orang lain serta seluruh kendali kehidupan keluarga sepenuhnya dipegang oleh ibu selain merapihkan rumah, mendidik anak-anak, dan melayani suami. Yang paling terpenting pola pikir IRT itu dalam melaksanakan aktivitas produktif, distributif dan konsumtif.

KPIRT berdasarkan pola sikap yang dimilki para IRT suku melayu Jambi dalam mengelola ekonomi keluarganya menggunakan beberapa perspektif yang dijadikan prinsip bagi mereka dalam menjalanka roda perekonomian keluarga diantaranya adalah melakukan tindakan untuk memprioritaskan apa yang menjadi kebutuhan, meningkatkan pendapatan, memperhatikan kebutuhan sekarang dan akan datang, menerapkan adat dan nilai-nilai budaya melayu Jambi dalam sendisendi kehidupan ekonomi, rasa tanggung jawab dan pendirian yang teguh dalam melakukan suatu tindakan.

KPIRT berdasarkan pola sikap yang dimilki para IRT suku melayu Jambi secara tidak langsung akan membentuk pola perilaku dari suatu tindakan yang dilakukan lebih intens sehingga menjadikanya suatu bentuk kebiasaan dalam mengelola ekonomi keluarganya. Beberapa perspektif yang dijadikan IRT dalam bentuk perilaku yaitu membiasakan menggunakan prinsip dalam menjalanka roda perekonomian keluarga diantaranya adalah berhemat dan memanfaatkan alam sekitar, mengatur keuangan, saling berbagi antar sesama, tolong menolong dan gotong rosyong, melakukan perencanaan dan diskusi, serta memiliki rasa berkecukupan.

\section{SIMPULAN}

Dari sudut pandang ekonomi feminis yang diwakili oleh para ibu rumah tangga suku melayu jambi bahwa dalam pendidikan ekonomi dalam keluarga harus mengajarkan bahwa dalam pola pikir, sikap dan perilaku harus mengedepankan adat bersendi syara', syara'bersendi kitabullah yang dipadupadankan dengan nilai-nilai kebudayaan seperti nilai tolong menolong, nilai kebersamaan, nilai kerjasama, nilai tanggung jawab, nilai kepasrahan, nilai perencanaan, nilai kesempatan, dan nilai kerja keras. Nilai-nilai tersebut diterapkan dalam menjalankan kehidupan berekonomi baik dilingkungan keluarga maupun masyrakat. Hal tersebut dilakukan untuk mencapai terciptanya economic wellbeing dengan sifat IRT yang motehrhood dan altruismenya. Berdaasarkan paparan tersebut diketahui bahwa kontribusi perspektif ekonomi feminis dalam pendidikan ekonomi keluarga suku melayu Jambi telah menerapkan perilaku-perilaku yang mencerminkan ekonomi pancasila.

\section{DAFTAR PUSTAKA}

Abu \& Nur. 2001. Psikologi Perkembangan. Jakarta : Rineka Cipta.

Berik, G Meulen Rodgers, Y. and Seguino, S., 2009. feminist economics of Inequality, Development and Growth. feminist economics 15(3):1-33

Bryant, W. 1995. The economic organization of the household. New York, Cambridge University Press.

Krishnaraj M. 2006. Is 'gender' easy to study? Some reflections. Economic and Political Weekly 41(42):4440-4443.

Kyridis, A., Tsakiridou, E., Zagkos, C., Koutouzis, M. \& Tziamtzi, C. (2011). "Educational inequalities and school dropout in greece". International Journal of Education, Vol 3, No. 2: 1-15

Lantara, Niniek Fariati. 2015. The Roles of Woman as Leader and Housewife. Indonesian Moslem University, Urip Sumoharjo

Mayasari. 2015. Feminist Economy in Family Economic Education to Build Economic Morality of Pancasila. IOSR Journal of Economics and Finance (IOSR-JEF) Volume 6, Issue 6. Ver. II (Nov. - Dec. 2015), PP 35-40

Moleong. Lexy J. 2008.Metodologi Penelitian Kualitatif Edisi Revisi. Bandung : Remaja Rosdakarya

Samuelson. Nordhaus, 2003, Ilmu Mikro Ekonomi, PT Media Global Edukasi,Jakarta.

Saroni, Muhammad. (2011). Orang miskin bukan orang bodoh. Yogyakarta:Bahtera Buku.

Sudarmanto, R.Gn. Konsep Dasar Ekonomi Pancasila, http://blog.unila.ac.id/radengunawans/files/2010/07/MakalahFilsafat-Ilmu.pdf, diakses pada 06 November 2010.

Sukwiaty, dkk. 2007. Ekonomi. Jakarta: Yudistira

Sutisna. 2002. perilaku konsumen dan komunikasi pemasaran, Bandung : remaja

Sweetman, C., 2008. Feminist economics. Background paper: From poverty to power.Oxfam International

Zeitlin M, Brown L. 1995. Household Nutrition Security: A Development Dilema.: Food Agricultural Organization. Roma. 